\title{
Groundwater pumping versus surface-water take
}

\author{
Husam Musa Baalousha ${ }^{1}$
}

Received: 14 April 2016/Accepted: 16 April 2016/Published online: 26 April 2016

(c) Springer International Publishing Switzerland 2016

\begin{abstract}
Surface-water bodies and aquifers are normally connected and it is widely recognised they should be treated as one entity. Numerous studies were done to analyse the effect of groundwater pumping on nearby streams, however, little is known on the differences of effects between surface-water take and a pumping well of equal rate. The question, which often arises by water resources managers and allocation authorities, is whether to allocate or consent-transfer from a surface-water body or from an aquifer. This study explores the different effects of each case and makes a comparison using analytical analysis and numerical models. A hypothetical model is presented where two cases are considered: (1) a stream water take through a diversion and (2) a pumping well. In both cases, the drawdown and water budget of surface and groundwater are presented. Results show the pumping well produces high drawdown in the aquifer, and induces stream leakage. The stream leakage results in stream level drop. It takes a long time for such a system to stabilise or to reach a steady state. In contrary, the direct stream water take produces much lower drawdown in the aquifer, albeit higher drop in stream water level. The latter case stabilises and reaches steady state conditions considerably faster than the first one. These results reveal it is recommended to allocate from surface-water bodies than aquifers as the impact is less and for a shorter time, given the same allocated volume of water.
\end{abstract}

Husam Musa Baalousha

Baalousha@web.de

1 Qatar Environment and Energy Research Institute (QEERI), Hamad Bin Khalifa University (HBKU),

PO Box: 5825, Doha, Qatar
Keywords Water allocation - Groundwater modelling · Surface-water · Stream depletion · Modflow · Analytical solution

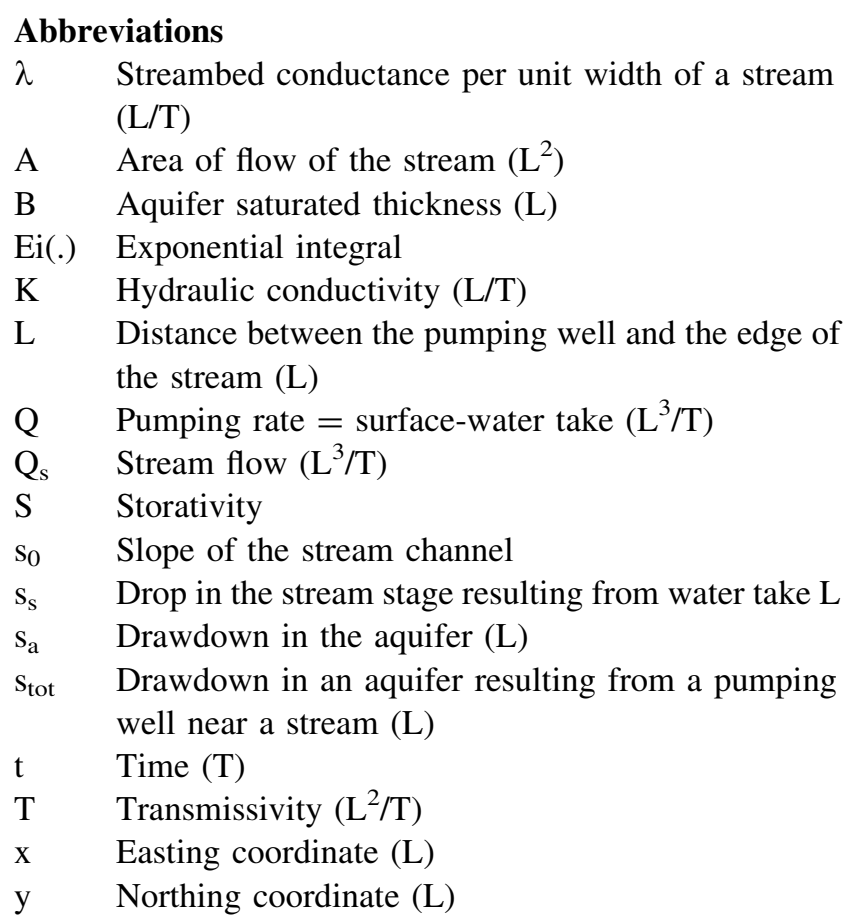

\section{Introduction}

Groundwater and surface-waters are normally hydraulically connected, and thus, should be treated as a single source (Winter et al. 1998; Baalousha 2009). Pumping of groundwater near a stream may capture flow that otherwise 
would end up in the stream or induce a flow from the stream to the aquifer. It is important to maintain a minimum level of surface-water flow to protect the stream habitat and the ecology through a proper integrated water resources management.

Coupling surface and groundwater flow can be done through analytical or numerical models (Baalousha 2012a, b). Numerous studies developed analytical models for the effect of groundwater pumping on a nearby stream (i.e. Theis 1941; Hantush 1965; Hunt 1999; Zlotnik and Tartakovsky, 2008). Numerical models are more popular than analytical models due to their flexibility and ability to handle complex problems, especially on the catchment scale.

These models can help decision makers, planners and water management authorities identify the effect of groundwater and surface-water allocation. In droughts and peak summer periods when stream flow is below a threshold limit, the local authorities impose ban on surfacewater take. When the ban is imposed, sometimes farmers ask for allocation of groundwater in lieu of their allocated surface-water. It is unclear which has more adverse impact on the aquifer/stream balance on the long term.

This study aims at analysing the impact of a pumping well versus a surface-water take of equal rate. In each case, the aquifer drawdown and drop in surface-water level is analysed analytically and numerically.

\section{The conceptual model}

The conceptual model comprises two cases: (1) a pumping well alone near a stream and (2) a surface-water take alone in the stream. The rate of pumping from the aquifer equals the take rate from the stream. Figure 1 shows a schematic diagram of the hypothetical conceptual model. In both cases it is assumed the aquifer and the stream are in steady state conditions, and the stream is in hydraulic contact with the aquifer, as shown in the figure. It is assumed the aquifer is confined, isotropic and homogeneous and a clogging layer exists at the bottom of the stream. The pumping well is at a distance $L$ from the edge of the stream. Before pumping it is assumed that both groundwater head and stream stage are equal. This conceptualisation is used as a basis for analytical solution derivation and for numerical modelling.

\section{Analytical solutions}

In the following section, the effect of pumping and water take from the stream is assessed using analytical models for drawdown estimation.

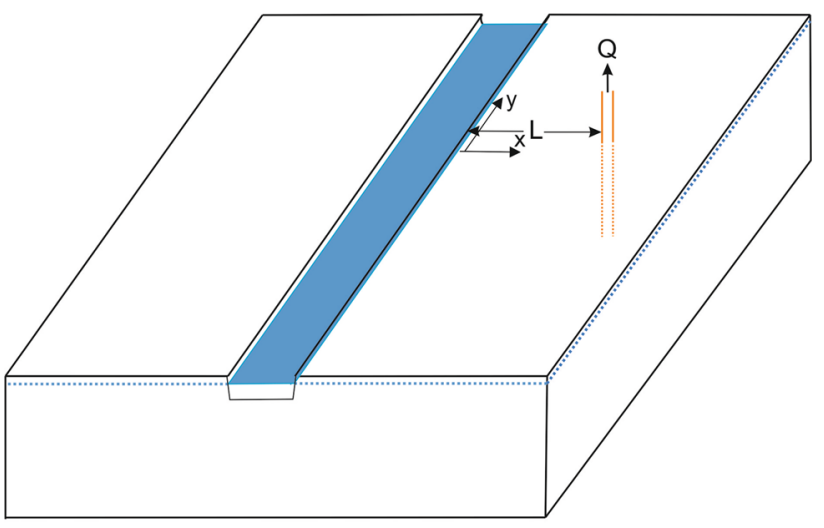

(a) A pumping well only

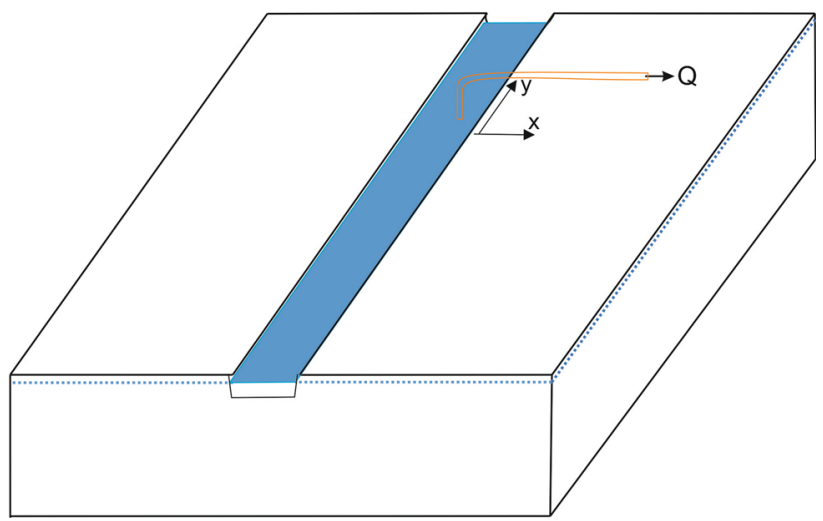

(b) Surface water take only

Fig. 1 A pumping well (top) and a surface-water take (bottom)

\section{Surface-water take impact}

This is the case depicted in Fig. 1b. The drawdown in the aquifer should satisfy the following boundary value problem:

$T \frac{\partial^{2} s_{a}}{\partial x^{2}}=S \frac{\partial s_{a}}{\partial t}$

Where $s_{a}$ is the drawdown in the aquifer. The boundary conditions of Eq. (1) are: $s_{a}(0, t)=$ drop in stream stage, $s_{s}$. Initial drawdown is $0 ; s_{a}(\infty, t)=0$.

The solution of Eq. (1) is (Carslaw and Jaeger 1959):

$$
\begin{aligned}
s_{a}= & s_{s} \operatorname{erfc}\left(\sqrt{\frac{S x^{2}}{4 T t}}\right) \\
& -s_{s} \exp \left(\frac{\lambda^{2} t}{4 T S}+\frac{x \lambda}{2 T}\right) \operatorname{erfc}\left(\frac{\lambda \sqrt{t}}{2 \sqrt{T S}}+\frac{x \sqrt{S}}{2 \sqrt{T t}}\right)
\end{aligned}
$$

If the stream has no clogging layer (i.e. $\lambda$ is too large) then the second term of the right-hand side of Eq. (2) becomes 0 . It should be noted the aquifer drawdown $s_{a}$ depends on $x$ only, as $\mathrm{s}_{\mathrm{s}}$ is assumed to be steady and constant along the stream. 


\section{Groundwater pumping impact}

In the case of a pumping well without surface-water take (Fig. 1a), drawdown in the aquifer is a combination of the pumping well drawdown and stream depletion (Baalousha 2012c). As the well continues pumping, it induces stream depletion. This induced flow compensates for some of the drawdown. The total drawdown in the aquifer $\left(\mathrm{s}_{\mathrm{tot}}\right)$ is (Hunt 1999; Baalousha 2012c):

$$
\begin{aligned}
s_{t o t}= & \frac{Q}{4 \pi T} E i\left(-\frac{S\left((L-x)^{2}+y^{2}\right)^{2}}{4 T t}\right) \\
& -\frac{Q \lambda}{8 \pi T^{2}} \int_{0}^{\infty} E i\left(-\frac{\left.S\left((L-x)^{2}+y^{2}\right)^{2}\right)}{4 T t}\right) \exp (-\lambda \eta / 2 T) d \eta
\end{aligned}
$$

If the stream is not hydraulically connected to the aquifer (i.e. $\lambda=0$ ), then Eq. (3) becomes the well-known Theis's solution of drawdown in a confined aquifer (Theis 1935).

Obviously, drawdown in the first case is independent off $y$, but varies if $s_{s}$ changes. The drawdown in Eq. (3) varies in both $\mathrm{x}$ and $\mathrm{y}$ directions, as the drawdown from a pumping well propagate horizontally.

Comparing Eqs. (2) and (3), it can be shown that If the streambed conductance is high and the stream is in full connection to the aquifer, then Eq. (3) is reduced to the image-well theory solution (Baalousha 2012c), and Eq. (3) reduces to Theis's solution (Theis 1935). In either case,the drawdown in the case of a pumping well $\left(\mathrm{S}_{\mathrm{tot}}\right)$ is larger than the drawdown in the case surface-water take.

\section{Numerical model}

To quantify the effect of both cases, a numerical model was developed for a surface-water take and a pumping well. The model uses a finite difference uniform grid, with dimensions 5000 by $5000 \mathrm{~m}$. The grid size is 50 by $50 \mathrm{~m}$, and the MODFLOW-2000 code was used (Harbaugh et al. 2000) for simulation. The stream routing package (SFR2) was used to simulate surface-water flow with groundwater connection (Niswonger and Prudic 2010). A stream is flowing in the middle of the grid, as shown in Fig. 2. The aquifer is confined and the stream is in hydraulic connection with the aquifer. Hydraulic properties of the model are shown in Table 1. Prior pumping or surface-water take, the aquifer and the stream are in static equilibrium; that is, change in aquifer storage or groundwater level is 0 .

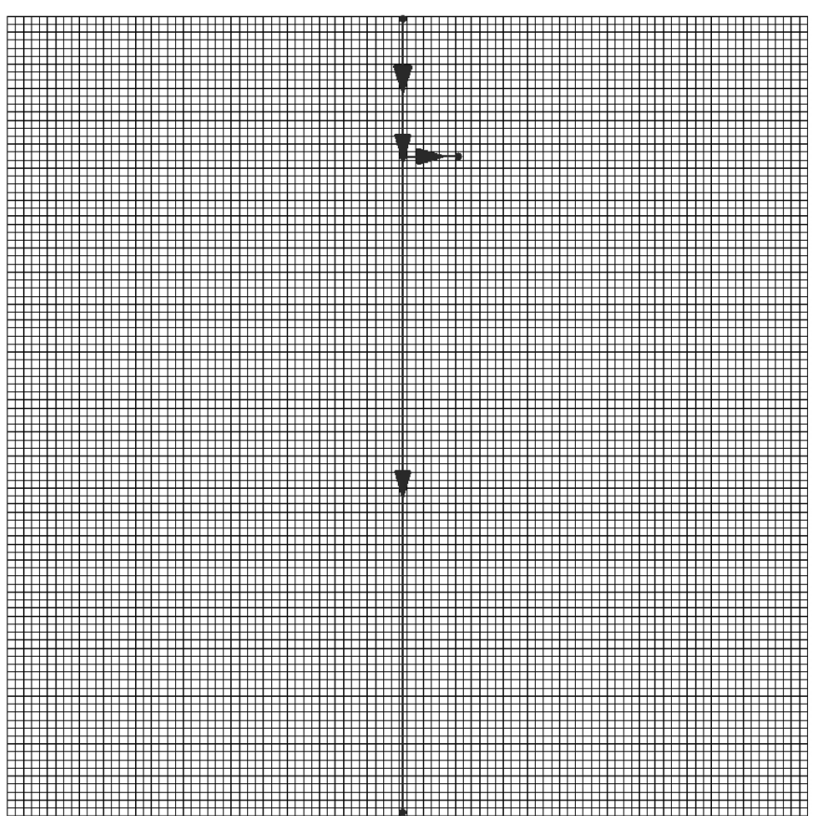

Fig. 2 Finite difference grid and stream location

\section{Surface-water take case}

In this case the stream has a diversion, as shown in Fig. 2, for a side canal with a take rate of $5000 \mathrm{~m}^{3} /$ day. This canal has no connection with the aquifer. The stream properties are listed in Table 2.

The model was run for 1000 days with 100 stress periods of 10 days each. Results are obtained at the end of the simulation periods, which include aquifer drawdown and the total water budget.

\section{Ground water pumping}

In this case the diversion canal was removed and a pumping well was placed in the aquifer at the same rate of surface-water take $\left(5000 \mathrm{~m}^{3} /\right.$ day $)$. All aquifer parameters are as listed in Table 1. The model was run for 1000 days, as with the pervious case.

\section{Results and discussion}

The drawdown (i.e. drop in groundwater head) in both cases at the end of simulation period is shown in Fig. 3. Obviously, the drawdown in case of a pumping well is much larger than the case of a surface-water take. The maximum drawdown in the aquifer in the case of stream 
Table 1 Values of aquifer/ stream parameters

\begin{tabular}{lll}
\hline Symbol & Parameter & Value \\
\hline$\lambda$ & Streambed conductance per unit width of stream & $0.1 \mathrm{~m} /$ day \\
$\mathrm{A}$ & Area of flow of the stream & $0.8 \mathrm{~m}^{2}$ \\
$\mathrm{~B}$ & Aquifer saturated thickness & $20 \mathrm{~m}$ \\
$\mathrm{~K}$ & Hydraulic conductivity & $30 \mathrm{~m} / \mathrm{day}$ \\
$\mathrm{L}$ & Distance between the pumping well and the edge of the stream & $1000 \mathrm{~m}$ \\
$\mathrm{n}$ & Manning roughness & 0.025 \\
$\mathrm{Q}$ & Pumping rate = surface-water take rate & $5000 \mathrm{~m}^{3} / \mathrm{day}$ \\
$\mathrm{Q}_{\mathrm{s}}$ & Stream flow at the first reach upstream & $12000 \mathrm{~m}^{3} /$ day \\
$\mathrm{S}$ & Storativity of the aquifer & 0.001 \\
$\mathrm{~s}_{0}$ & Slope of the stream channel & 0.0001 \\
\hline
\end{tabular}

Table 2 Stream characteristics

\begin{tabular}{ll}
\hline Parameter & Value \\
\hline Stream flow & $12000 \mathrm{~m}^{3} /$ day upstream then routed \\
Manning roughness of the streambed & 0.025 \\
Thickness of the streambed & $1 \mathrm{~m}$ \\
Streambed slope & $1 \mathrm{E}-06$ \\
Stream width & $2 \mathrm{~m}$ \\
Stream depth & $0.8 \mathrm{~m}$ upstream then routed \\
\hline
\end{tabular}
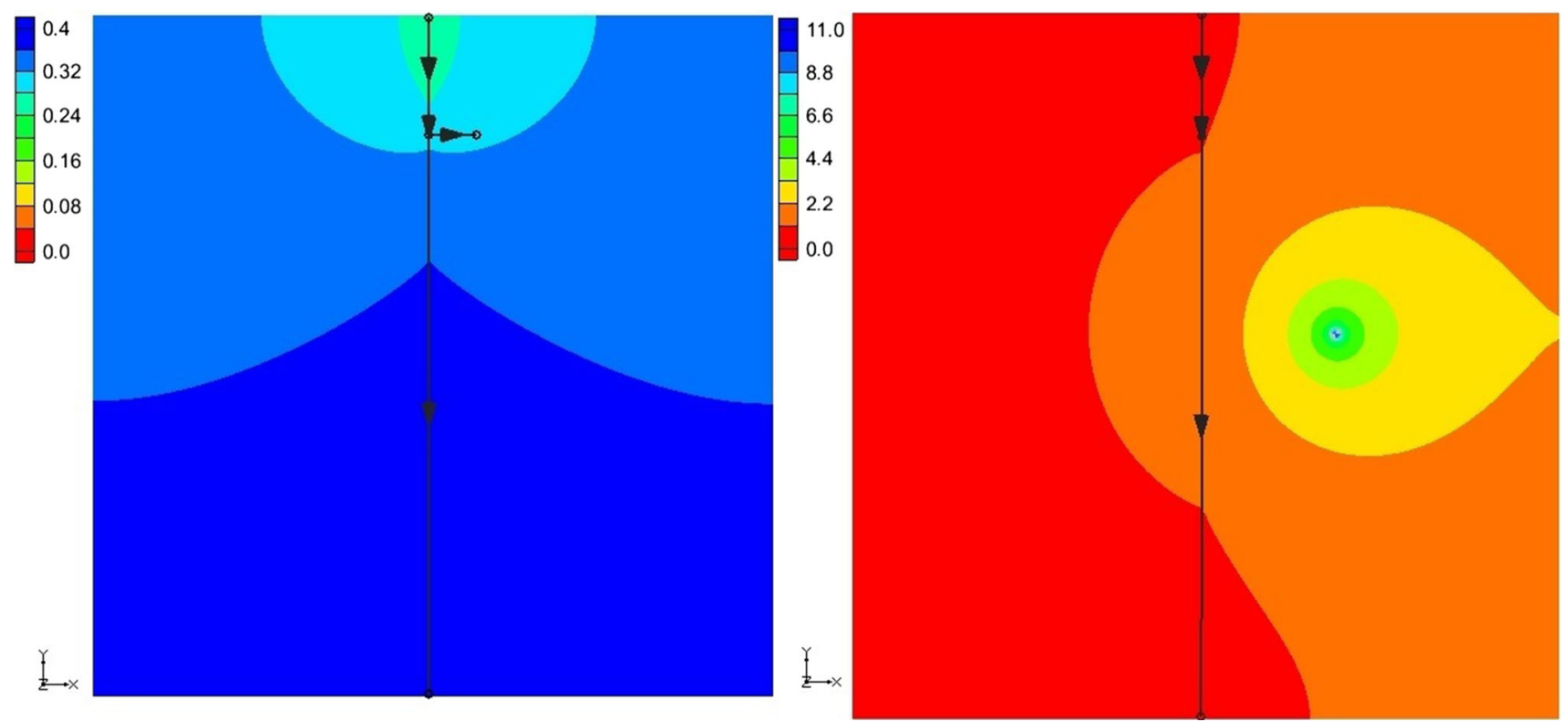

Fig. 3 Drawdown in meters resulting from a stream take (left) and a pumping well (right) at the end of the simulation period

take is only $0.7 \mathrm{~m}$, whereas it is $11 \mathrm{~m}$ in the vicinity of a pumping well. This is a clear indication that the stream water take produces less drawdown in the aquifer.

In addition to drawdown, water budget analysis over the simulation period was done. Prior pumping or surfacewater take, there was no exchange of water between the stream and the aquifer. Both the aquifer and the stream have a water head/level of $0.7 \mathrm{~m}$. Figure 4 shows the changes in water budget rates over the simulation period for the case of the stream water take. The surface-water take of $5000 \mathrm{~m}^{3} /$ day comes mainly from the stream but induces also a flow from the aquifer $\left(500 \mathrm{~m}^{3} /\right.$ day), as demonstrated in Eq. (2). As a consequence, the water level in the aquifer drops, as shown in Fig. 3, which reduces the flow from the stream to the aquifer. In addition, the reductions in stream level downstream the diversion and 


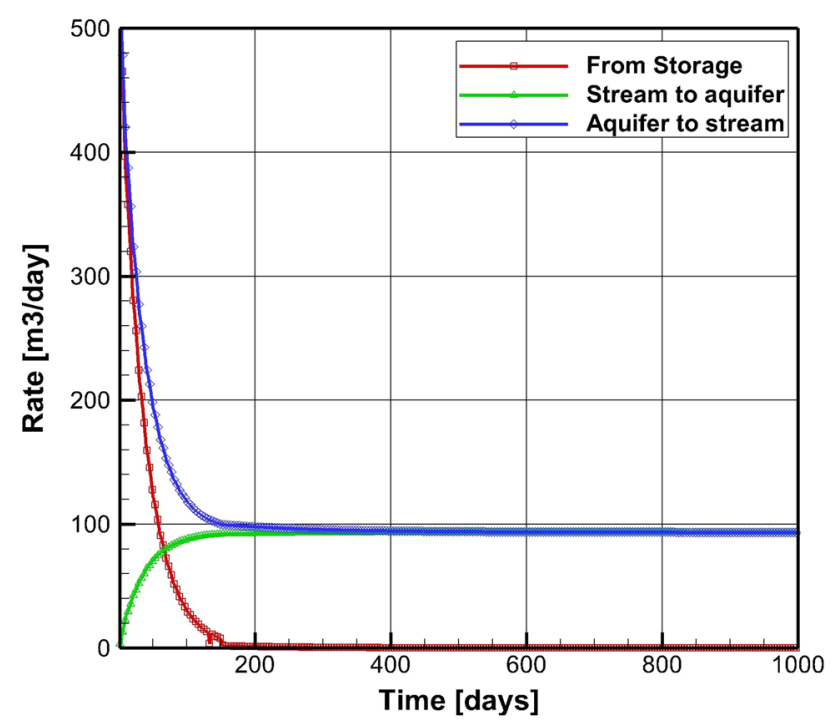

Fig. 4 Water budget rate for the case of stream water take

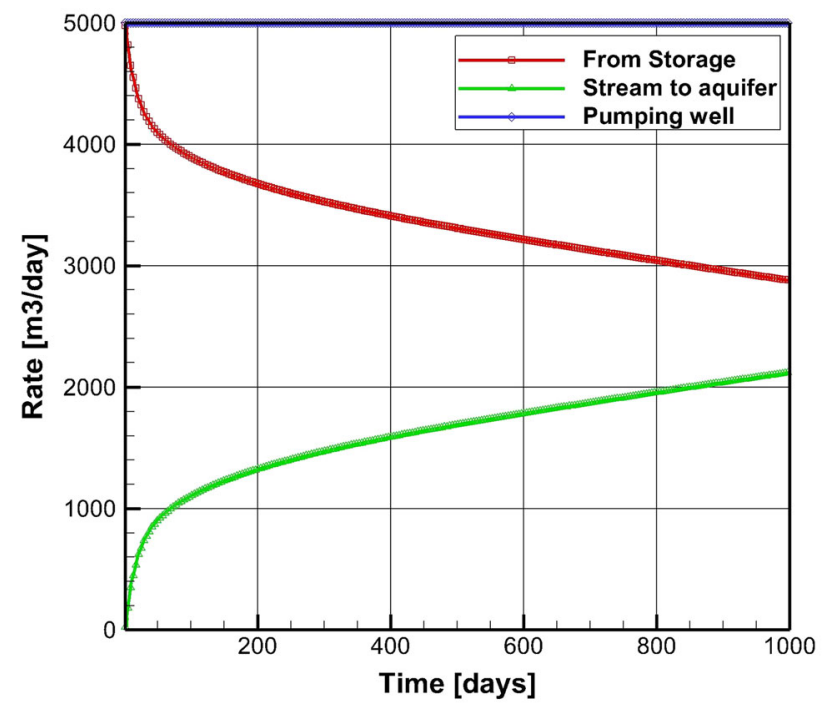

Fig. 5 Water budget rate for the case of a pumping well

the resulting drawdown in the aquifer induce stream leakage to the aquifer upstream the diversion. After around 200 days, the aquifer and stream comes to equilibrium, as shown in Fig. 4. The maximum drawdown in the aquifer is $0.4 \mathrm{~m}$, which is equal to the maximum drop in stream level downstream the diversion.

Similarly, the case of a pumping well is depicted in Fig. 5, which has obviously more impact than the first case. At the beginning of pumping, the entire volume of water comes from the storage, which quickly induces stream leakage to the aquifer. As pumping continues, the loss from the storage decreases and compensated by more flow from the stream (refer to Eq. 3). The case does not reach equilibrium even after 2000 days of pumping. This is evident in the high drawdown of $11 \mathrm{~m}$ at the well head. The maximum drop in stream level after 2000 days is $0.17 \mathrm{~m}$, compared to $0.4 \mathrm{~m}$ in the case of stream take.

\section{Conclusions}

This study compares the effects of groundwater pumping versus stream water take, of equal rate and amount. In water resources allocation and management, a question is always being asked whether to allocate from a stream or from an aquifer. In particular in dry spells, when a ban is imposed by water authorities on surface-water bodies (i.e. rivers and streams), many farmers ask for consent transfer from surface to groundwater. It is widely known that stream are more sensitive and more prone to drought than groundwater, but the effects of aquifer pumping versus direct take is never understood, to the best of the author knowledge. In this paper, the effects have been analysed using analytical and numerical models. Both numerical and analytical models show the aquifer drawdown resulting from a pumping well is much higher than it in the case of a stream water take. In addition, the effect on the storage is substantial in the case of a pumping well, as the entire pumped volume comes from the aquifer storage in the beginning before being compensated for by stream leakage. On the other hand, the effect of a stream water take on the stream level is higher than the case of a pumping well, but this drop can be quickly recovered once the pumping cease.

As a conclusion, it is recommended not to transfer allocation from surface-water body to groundwater, as the latter case has more adverse impact than the first, and it lasts for longer. Recovery of groundwater level takes much longer time than surface-water drop.

\section{References}

Baalousha H (2009) Stochastic water balance model for rainfall recharge quantification in Ruataniwha Basin, New Zealand. Environ Geol 58(1):85-93

Baalousha HM (2012a) Characterisation of groundwater-surfacewater interaction using field measurements and numerical modelling: a case study from the Ruataniwha Basin, Hawke's Bay. New Zealand. Appl Water Sci 2(2):109-118

Baalousha HM (2012b) Modelling surface-groundwater interaction in the Ruataniwha basin, Hawke's Bay, New Zealand. Environ Earth Sci 66(1):285-294

Baalousha HM (2012c) Drawdown and stream depletion induced by a nearby pumping well. J Hydrol 466:47-59

Carslaw HS, Jaeger JC (1959) Conduction of heat in solids, 2nd edn. Oxford University Press, Clarendon Press, Oxford, p 510

Hantush MS (1965) Wells near streams with semipervious beds. J Geophys Res 70:2829-2838 
Harbaugh AW, Banta ER, Hill MC, McDonald MG (2000) MODFLOW-2000, the U.S. Geological Survey modular ground-water model-modularization concepts and the ground-water flow process: U.S. Geological Survey Open-File Report00-92, p 121

Hunt B (1999) Unsteady stream depletion from ground water pumping. Ground Water 37:98-102

Niswonger RG, Prudic DE (2010) Documentation of the streamflowrouting (SFR2) package to include unsaturated flow beneath streams - a modification to SFR1. U.S. Geological Survey Chapter 13 of Section A, Ground Water, of Book 6, Modeling Techniques
Theis C (1935) The relation between the lowering of the piezometric surface and the rate and duration of discharge of a well using ground-water storage. Transactions, American Geophysical Union, pp 519-524

Theis C (1941) The effect of a well on the flow of a nearby stream. Trans Am Geophys Union 22:734-738

Winter TC, Harvey JW, Franke OL, Alley WM (1998) Ground water and surface-water a single resource U.S. Geol Survey Circ 1139, p 87

Zlotnik VA, Tartakovsky D (2008) Stream depletion by groundwater pumping in leaky aquifers. J Hydrol Eng 13:43-50 